\title{
Editorial
}

\section{OUT OF THE SHADOWS...}

It has become a cliche in the United States to say that immigrants, particularly undocumented immigrants, live "in the shadows," that their experiences are hidden and their stories, unknown. Every once in a while, their hardships and suffering are brought to light - in news articles documenting the conditions of their lives in the United States, their sudden deaths resulting from some catastrophic "mistake" in a factory or natural disaster, their massive movements and firm responses to what is clearly an outrageous and shameful criminalization of men, women, and children in detention sites around the country; or in politicians' and/or the mainstream media's decision to highlight their "cultural" celebrations and iconic expressions. Once in a while, it is true, there are some public handwringing moments against, for example, the unconstitutional and inhumane treatment of immigrants and their children (many of whom are US born) currently held in detention. In recent years, these have even given way to a flurry of "national discussions," "special reports" on the evening news, and mainstream newspaper articles. ${ }^{1}$ The import has been the highlighting of what has become characterized increasingly as a "broken immigration policy."

The ongoing raids, detentions and deportations of immigrants occurring in communities across the United States, are perhaps the most shameful contemporary expression of the meaning of the phrase "living in the shadows." They occur suddenly, without warning, in the early morning hours, as ICE agents storm into the workplaces or houses where undocumented working people live, terrifying adults and children alike. Often these raids remain unknown to the general population - in part because the mainstream society does not care or want to know; but also because of another growing issue that is casting its own shadow on US society - that of the self-imposed silence of the mainstream media, including individual journalists. Yet although they remain in the shadows cast by the media's ongoing lies, distortions, and self-censorship, undoubtedly (and this too has become a cliché), the essential labor and services provided by immigrants - whether they are living in the shadows or not - are visible contributions to the well-being of our society, and certainly well known to politicians and the mainstream business community. Ironically, US history books and documentaries alike overflows with powerful images and details of the suffering endured by so many previous generations of immigrants. But this is small comfort for those who are members of this latest wave of newcomers - many of whom are, of course, Latino/as who are today suffering the indignities of false criminalization and its attendant treatment.
1 The recent series in The New York Times on the health of immigrants held in detention is a case in point. 
Like any other human beings, immigrants are never victims alone, nor are they ever victims to the end. While a growing - unprecedented - number of Latino/as are losing their battle to live in peace, to ensure their families' wellbeing, to earn a decent wage, their contributions are both a testament to their presence and an affirmation of their response to what is increasingly a hostile environment around the country. Whether through a stubborn insistence on affirming their humanity, their right to have rights, or through a persistence that can be traced back to a lack of alternative in their respective countries of origin, Latino/as have continuously responded to the ongoing attacks on their dignity, through civic protests. In so doing, they have called attention to the invaluable contributions they have made, and continue to make, to the overall well-being of US society and economy. Most often, their actions, like their contributions, remain in the shadows, undocumented in the history books, unknown to their fellow human beings in this society.

This issue of Latino Studies brings to light some of the largely invisible issues that bedevil and permeate the lives of immigrants. Moreover, it draws attention to little-known areas where Latino/as and members of the mainstream US society have come together around shared interests and concerns. Ultimately, these efforts have been beneficial to Latino/as in the face of the continuing discrimination they face in this country.

Flora González Mandrí presents a compelling description of the implications of the emotional trauma that immigrant children often suffer. Focusing on the case of the 14,000 Cuban children airlifted through Operation Pedro Pan, she grounds her discussion in the analysis of the work of two Cuban-Americans, a social scientist and a playwright, to highlight the long-term, hidden, and silenced effects of memory and trauma among children who - as a result of "governments and societies invested in the silencing of memory" - are forcefully displaced from their homelands. Her article is a reminder that no matter what the differences are between the lived experiences of today's arriving immigrants and the historical moment and circumstances of events such as Operation Pedro Pan, the consequences of displacement, particularly for the children involved, share certain commonalities with the kinds of traumas present day Latino immigrants face in terms of such issues as displacement and forced family separation.

Jane Juffer focuses on the experience of a little known, yet unusual congregation that has brought together Latino/as and members of a traditional Protestant church. Amistad Cristiana combines the religious traditions of lowpaid Latino/a workers with those of Protestants in northwest Iowa. Showing the inadequacy of the simplistic acceptance of the notion that Protestantism is linked to assimilation, she argues instead that the "hybrid" practices that define Amistad Cristiana are rooted in a Protestant work ethic that, at least at the present time, serves to bring together the dominant Dutch Reformed ethnic group with the Latino/a workers who currently work in the meat-packing plants 
and dairy farms. Thus, her article contributes to deconstruct the perception of the incompatability of these different traditions.

Ismael García Colón tells the story of migrant Puerto Rican farmworkers in a small farm community in western New York, who, in July 1966, protested against the image of Puerto Ricans' inferiority and the consequent police brutality and discrimination unleashed against them by the town of North Collins. In so doing, they affirmed their right to belong as citizens of this country.

Continuing the general theme of this issue, our annual Reflexiones Pedagógicas section brings to light both little-known issues and innovative pedagogical experiences within the Latino/a community today. Mirtha Anarella Cellitti Guillen, for example, provides an overview of various concerns (the traumatic effects of the circumstances under which children immigrate, parent and teacher interventions, health issues, etc.) that go "beyond educational interventions."

Mari Castañeda discusses the often overlooked potential for transformative learning through community-university partnerships. Focusing specifically on Latina/o media studies, she analyzes both the benefits and the limitations of this partnership for enhancing pedagogical practices. Finally, based on her experience teaching about Latino/a youth cultures, Raquel Rivera focuses on reggaeton, particularly from a gender and sexuality perspective, to argue for the use of blogging as both a pedagogical practice that benefits students and a learning experience for herself.

Clearly, invisibility takes various forms. As these essays suggest, however, Latino/as continue to marcar presencia, whether through protest, through forging local ties with other groups, and thus affirming the validity of shared differences; through recovering the past and making the invisible visible; or through the innovative teaching practices that continue to bring Latino/as out of the shadows, educating and informing ourselves and others about our experiences in this society.

Saludos!

Suzanne Oboler

John Jay College of Criminal Justice

City University of New York, NY

Latino Studies (2008) 6, 249-251. doi:10.1057/1st.2008.37 